\title{
O embalar da morte
}

EMÍLIA COSTA

Título: Dramatículos 2. Autor: Samuel Beckett. Encenação: Fernando Mora Ramos. Tradução e dramaturgia: Isabel Lopes. Design sonoro: Carlos Alberto Augusto. Desenho de luz: Carina Galante. Cenografia e figurinos: Teatro da Rainha. Interpretação: Isabel Lopes e Fábio Costa. Produção: Teatro da Rainha. Local e data de estreia: Sala Estúdio do Teatro da Rainha, Caldas da Rainha, 31 de Março de 2016.

\author{
Fecha-lhe os olhos \\ Que se lixe a vida \\ Fecha-lhe os olhos \\ Embala-a daqui \\ Embala-a daqui. \\ SAMUEL BECKETT, Cadeira de Embalar
}

No longo percurso do Teatro da Rainha, fundado, em 1985, por Fernando Mora Ramos (actor e encenador) e José Carlos Faria (cenógrafo), esta é a quarta incursão em Samuel Beckett, após Krapp - A Última Gravação em 1987, A Última Bobina em 2002 e Dramatículos 1 em 2015. Tal circunstância, associada à extensa experiência como encenador de Fernando Mora Ramos, sempre permitiria ao espectador confiar no sucesso do difícil desafio que encenar Beckett - génio da dramaturgia mundial, nascido na Irlanda em 1906 - continua a representar. Na realidade, depois de Shakespeare, Beckett é um dos dramaturgos mais encenados em Portugal, ainda que nem sempre com o rigor e talento que a sua obra reivindica.

A simplicidade aparente das peças de Beckett, sem a complexidade psicológica das personagens de Henrik Ibsen ou de August Strindberg, quase sem acção e com pouco ou mesmo sem movimento, cria por vezes a ilusão da facilidade, levando encenadores e actores a abordarem-nas superficialmente. Porém, se há teatro que exige um acentuado rigor de encenação e de interpretação, obrigando cada pormenor do texto, da voz, do som, da luz, do movimento, do cenário, dos figurinos e da maquilhagem a participar numa harmoniosa e cronometrada partitura cénica, é o de Beckett. 


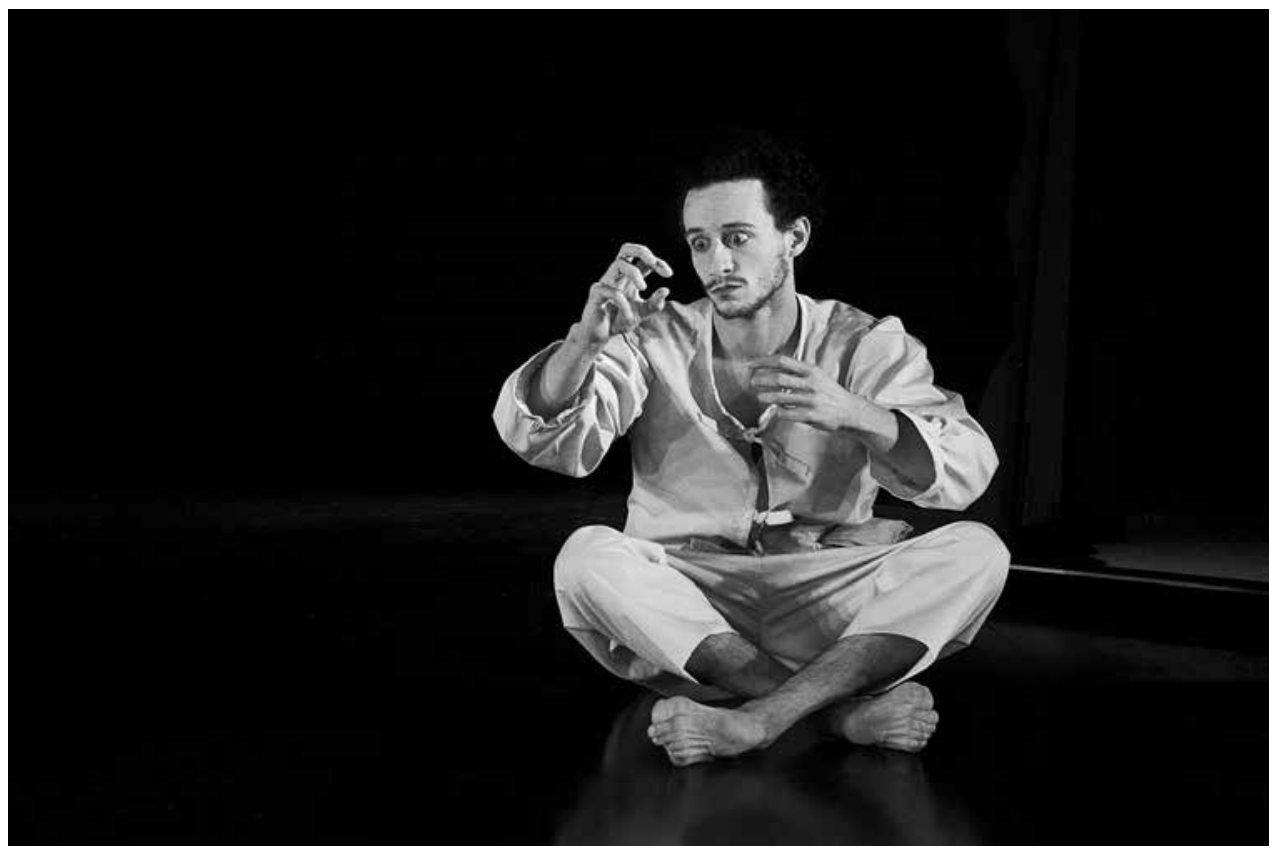

DRAMATÍCULOS 2, DE BECKETT, ENC. FERNANDO MORA RAMOS, TEATRO DA RAINHA, 2016 (FÁBIO COSTA), [F] PAULO NUNO SILVA

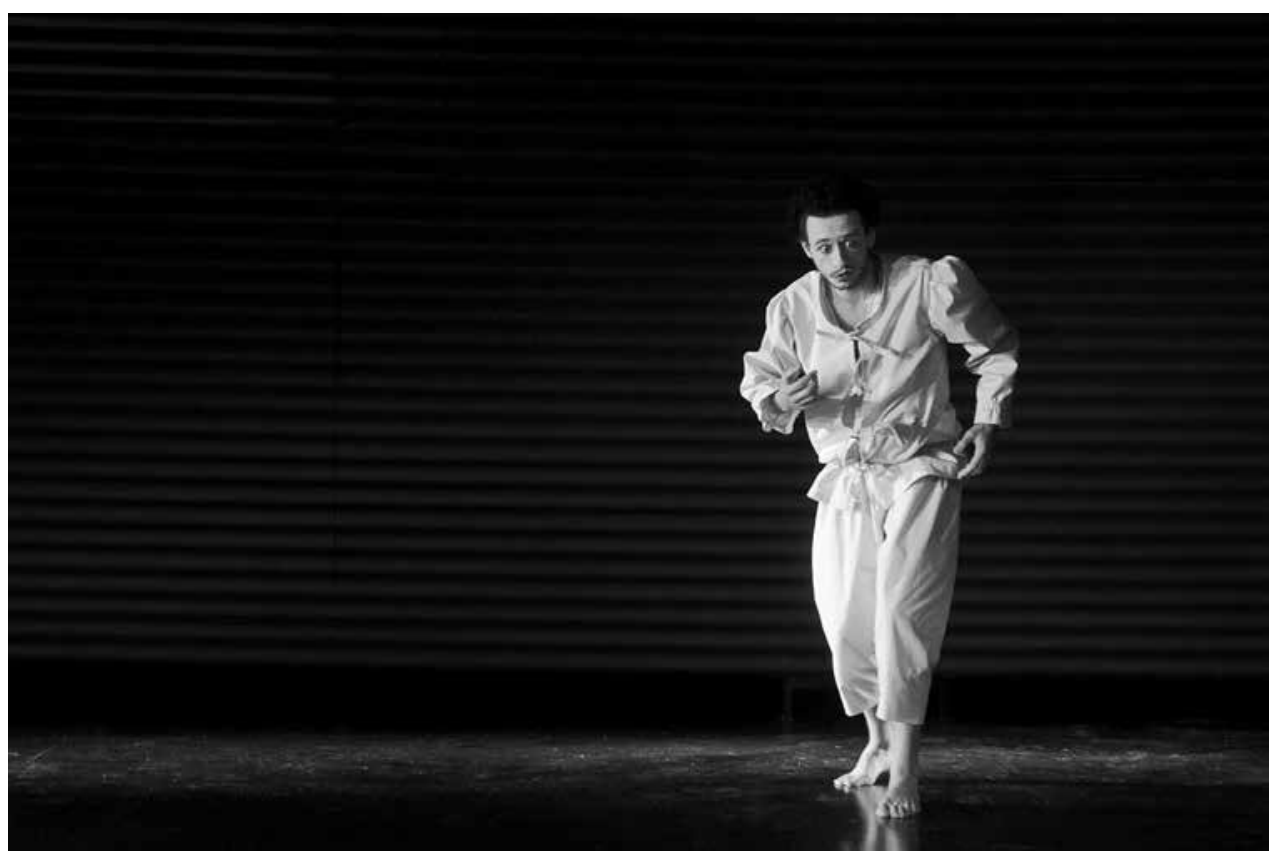

DRAMATÍCULOS 2, DE BECKETT, ENC. FERNANDO MORA RAMOS, TEATRO DA RAINHA, 2016 (FÁBIO COSTA), [F] PAULO NUNO SILVA 


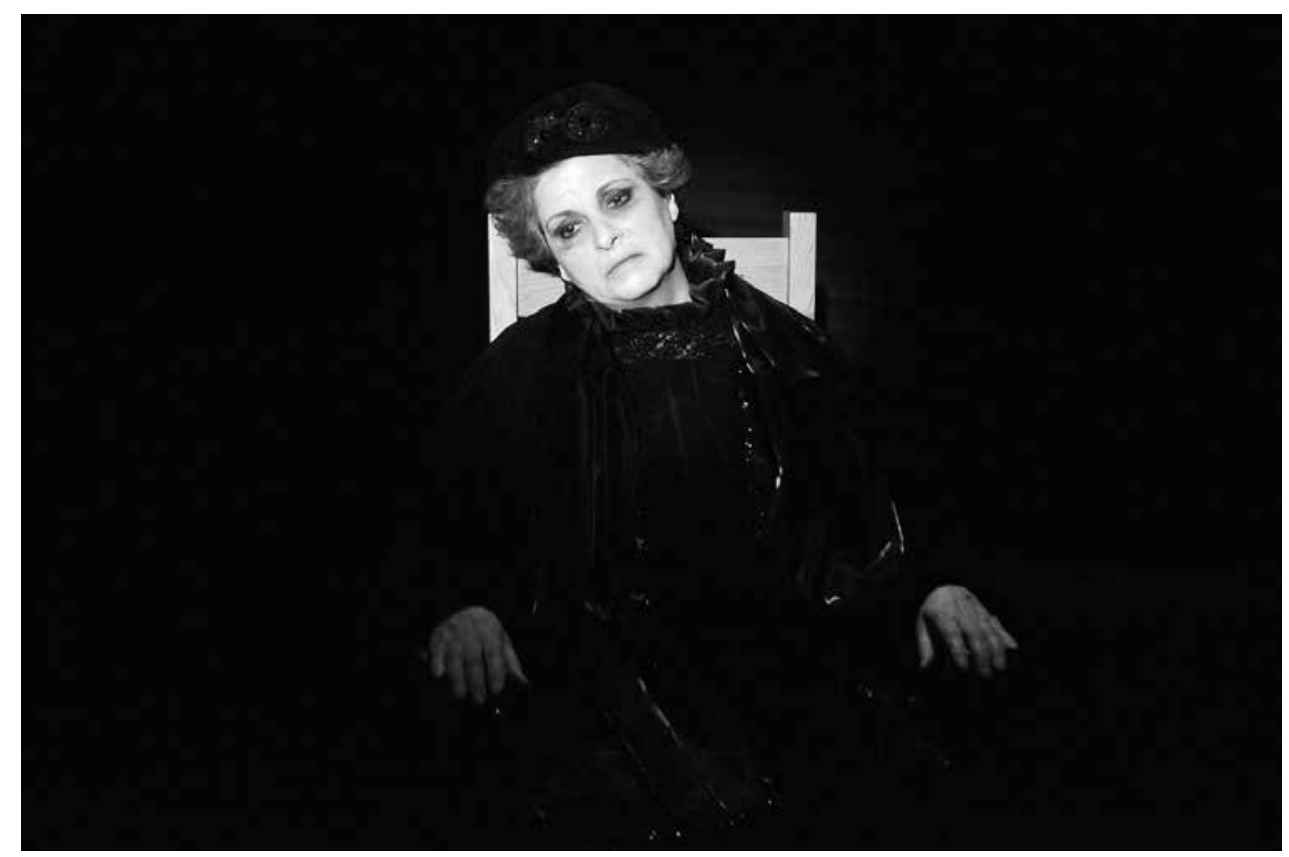

DRAMATÍCULOS 2, DE BECKETT, ENC. FERNANDO MORA RAMOS, TEATRO DA RAINHA, 2016 (ISABEL LOPES), [F] PAULO NUNO SILVA

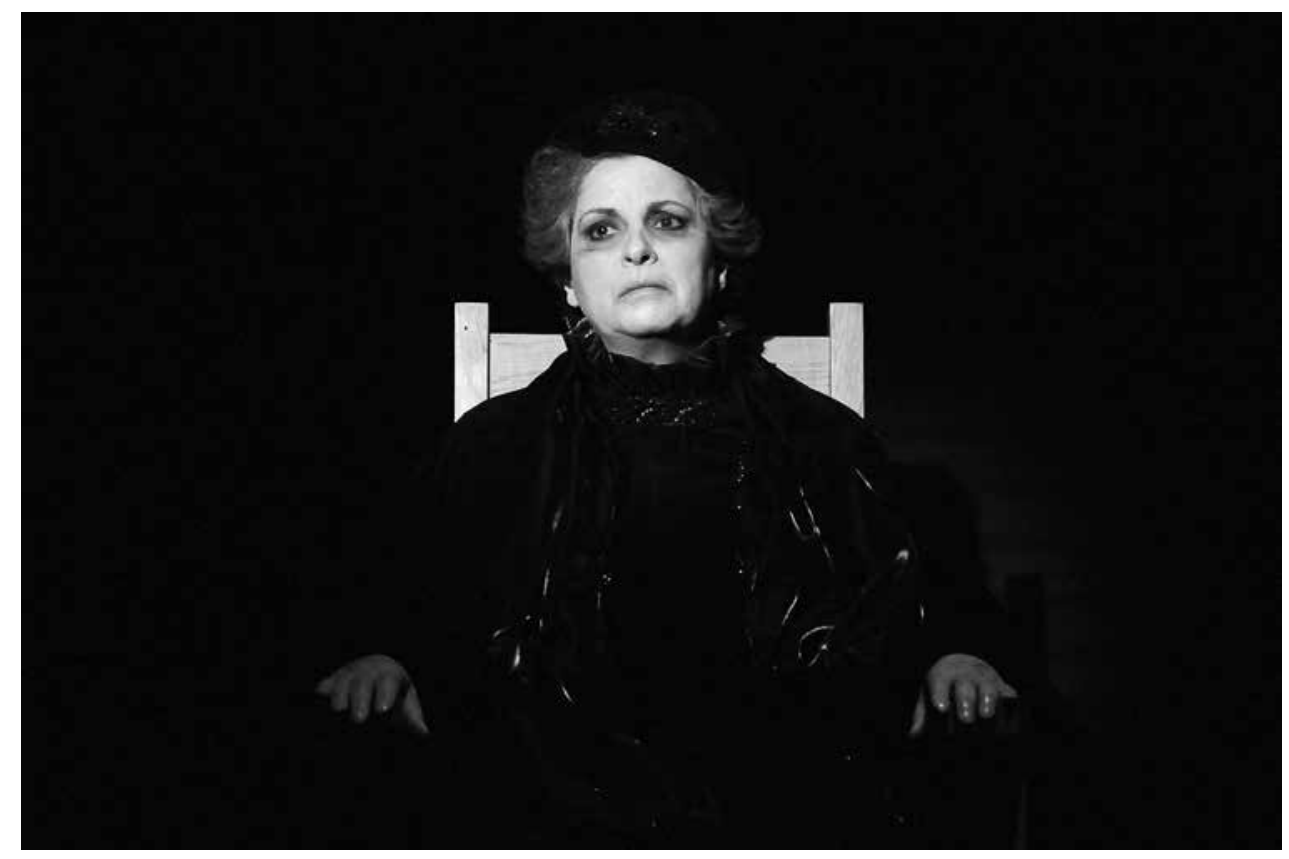

DRAMATÍCULOS 2, DE BECKETT, ENC. FERNANDO MORA RAMOS, TEATRO DA RAINHA, 2016 (ISABEL LOPES), [F] PAULO NUNO SILVA 
Em Dramatículos 2, foram seleccionadas três peças de curta duração: Eu não, Acto sem Palavras I e Cadeira de Embalar, escritas respectivamente em 1972, 1956 e 1981. A eleição destas peças não é arbitrária, representando todas elas, à sua maneira, um manifesto sobre o absurdo da vida humana. E se é verdade que esta é uma temática beckettiana, existe nesta inteligente escolha um acentuar mais compungido desse lamento pela incompreensibilidade do sentido da vida, ao eleger como arautos do sofrimento meros fragmentos do corpo humano, mais concretamente, a boca, as mãos e os olhos.

Efectivamente, em Eu não, sendo a boca, na versão cénica apresentada, o único elemento humano em palco, é esta que nos relata a vida de sofrimento e solidão de uma mulher de quase setenta anos; em Acto sem Palavras I, apesar de se encontrar em palco todo o corpo de um actor, são as suas mãos que nos revelam o percurso da evolução humana, bem como dos obstáculos e arbitrariedades com que incessantemente nos confrontamos; e, em Cadeira de Embalar, apesar de estarmos perante o corpo de uma actriz sentada na cadeira de embalar, são os olhos, enormes e trágicos, que, num desespero congelado, se destacam e nos falam.

No primeiro dramatículo, Eu não, Fernando Mora Ramos, partindo da versão inglesa e original da peça, onde constava a figura do Auditor - personagem muda, praticamente imóvel (pois apenas lhe estavam destinados quatro pequenos gestos) e coberta por uma jilaba, que se limitava a ouvir a $\mathrm{Voz}$-, optou por prescindir dessa personagem, no seguimento do que o próprio Beckett veio a fazer em versão posterior (na versão francesa), em 1975 .

Assim, em palco, num fundo totalmente preto, apenas existe, à direita e em cima, um buraco, de onde surge uma boca, mais concretamente dois lábios pintados de vermelho, para onde converte toda a iluminação, e, dessa boca, em tom baixo que começa a subir até se tornar claustrofóbico, jorra uma torrente de palavras, de uma mulher, uma mulher de quase sessenta anos, afinal não, quase setenta?, que fala de si própria como se fosse de outra, em frases rápidas, vertiginosas, repetitivas, numa subtileza de sentimentos, em tom quase alegre, que até poderíamos achar que estava alegre, não fora a história de crueldade, sofrimento e solidão que nos narra, o grito que lança a meio do espectáculo e que nos arrepia, ou as súbitas e inesperadas interrupções que faz e que nos lançam num angustiante silêncio.

Isabel Lopes, actriz de eleição do Teatro da Rainha, tem em Voz um desempenho imaculado, demonstrando um ímpar virtuosismo vocal e 
intensidade emocional, reveladores não só do seu talento como actriz como da sua sensibilidade artística. A quantidade de texto que, enquanto actriz, Isabel Lopes teve de decorar, a velocidade com que teve de transmiti-lo e as múltiplas inflexões de voz que teve de conseguir invocar, dando, em simultâneo, ao seu desempenho, uma certa sensação de leveza, reveladores da sua pródiga maturidade artística, camuflam as exigências e complexidades desta personagem, razão por que Billie Whitelaw, actriz elegida para a sua representação, na estreia londrina em 1973, relatou mais tarde momentos de verdadeira tortura durante o período em que decorou o texto, bem como situações de privação sensorial já em cena. Essa será igualmente a razão pela qual esta peça tem sido tão poucas vezes representada em Portugal, depois da sua estreia, em 1983, pela Companhia de Teatro de Lisboa, através da lendária criação da actriz Graça Lobo.

Em Acto sem Palavras 1, o jovem actor Fábio Costa, em estágio no Teatro da Rainha, num sólido desempenho, revela-nos a fisicalidade e a violência constantes dos processos de aprendizagem humana. Num cenário inicialmente despojado, mas onde vão surgindo, anunciados por um apito, e vindo de cima (do céu?) vários objectos (uma árvore, uma tesoura, uma pequena garrafa de água, três cubos de diferentes dimensões e uma corda com nós), o Homem, inocente e ingénuo, através do tacto e da contínua experimentação, num ziguezaguear de avanços e recuos, procura compreender o que o rodeia, na busca incessante de um sentido, até que, por fim, depois de repetidas quedas, resultantes da ilogicidade despótica e prepotente de quem (Deus?) lhe determina a imponderabilidade do destino, impedindo-o inclusive do suicídio, simplesmente desiste, numa desconcertante apatia. Numa breve peça sem palavras, Beckett elabora uma complexa e perturbante metáfora da existência humana desde o nascimento até à morte.

A iluminação branca e intensa que rodeia o Homem no espaço confinado do palco, bem como o apuro técnico e sonoro com que lhe são apresentados os vários objectos, numa espécie de jogo sádico, acentuam o seu enclausuramento e transformam-no em mero joguete de entretenimento ou de cobaia laboratorial.

Em Cadeira de Embalar, último dramatículo desta selecção, a Mulher, numa criação modelar de Isabel Lopes, já velha ou precocemente envelhecida, toda vestida de preto, em posição estática, sentada numa cadeira de embalar, agarrada com as mãos às extremidades dos braços da cadeira, com grandes olhos destacados pela perfeição da maquilhagem, 
contracena com a sua voz gravada, num belo e longo poema fúnebre. Esta Mulher, tal como as duas personagens anteriores, aguarda pela morte, único e verdadeiro alívio contra o desconsolo da solidão, mas, desta vez, essa espera é embalada, quer pelo cadenciar do baloiçar da cadeira, quer pelo recital monótono e compassado de um poema, transportando personagem e espectadores ao entorpecimento, à aceitação conformada da morte. A luz, ao acentuar os olhos da Mulher, esses olhos de uma tristeza petrificada, intensifica a crueza da desesperança humana, que apenas sossegará quando, no final, os olhos se fecharem e o espectro dessa vivência moribunda se transformar em nada.

A orquestração perfeita do desenho sonoro por Carlos Alberto Augusto, o desenho de luz por Carina Galant e as interpretações exemplares de Isabel Lopes e Fábio Costa, irrepreensivelmente dirigidas pelo maestro Fernando Mora Ramos, proporcionou-nos a delicadeza sensitiva de um espectáculo poético e musical memorável.

A peça Dramatículos 2 estreou-se na Sala Estúdio do Teatro da Rainha, nas Caldas da Rainha, a 31 de Março de 2016, deslocando-se, posteriormente, em Maio, ao O'Culto da Ajuda, em Lisboa, e, em Novembro, ao Mosteiro de São Bento da Vitória, no Porto, levando aos grandes centros o teatro que se faz por este país fora, numa demonstração de qualidade e rigor, em defesa da essencial e indispensável descentralização da actividade teatral.

Fernando Mora Ramos, num acerto cénico de elevada qualidade, numa época em que se valoriza a originalidade em detrimento da qualidade, assumindo o risco de respeitar, no essencial, as didascálias minuciosas e precisas de Beckett, criou um espectáculo intenso, dramático e sensorial, num registo interpretativo de grande mestria, contribuindo para a dignificação da actividade teatral na sua incontornável vertente artística. 